\title{
Food from micro-organisms
}

\section{By Brian KIrsop, AFRC Food Research Institute, Colney Lane, Norwich $\mathrm{NR}_{4} 7 \mathrm{UA}$}

Micro-organisms are today widely used in the manufacture of food and drink, acting primarily as production agents rather than as principal raw materials. They play an important role in the conversion of ingredients into food, for example, in the preparation of bread, cheese, yoghurt and alcoholic drinks but, although some microbial cells are ingested when consuming these products, they do not represent a major source of protein, carbohydrate or fat. In the next two decades the role of microbes as food-manufacturing aids seems likely to expand. The present paper considers whether the use of micro-organisms as major ingredients of food is also likely to increase. Instances where microbial biomass is itself a food are relatively rare; at the present time the only substantial examples are the macrofungus, Agarica bisporus, and other species of mushroom. The annual consumption of these was estimated by Hayes \& Wright ( 1979 ) to amount to about 900000 tonnes.

Because their gross composition may closely resemble that of conventional foods, micro-organisms are potentially-useful ingredients. Individual microorganisms grown in similar circumstances differ in composition and much information has been summarized by Laskin \& Lechevalier (1973). It is possible to vary composition by changing the circumstances in which growth takes place (Rose, 1979). Organisms which are growing rapidly contain a high content of protein, while biomass with higher contents of storage carbohydrate or lipid or both, and less protein, is produced when the micro-organism continues to metabolize carbon compounds after growth has ceased. There are thus strong possibilities for tailoring microbes for particular uses. The protein content may have high biological value, especially when methionine supplementation is used (Levi et al. 1979). It is important to recognize that the nutrients in microbial biomass may be inaccessible because the cell wall or membranes of the organism may not be broken down by human enzymes; in this case it may be necessary to disrupt the cell before consumption.

Micro-organisms commonly contain essential micro-nutrients, such as vitamins, and indeed, as in the case of the yeast Saccharomyces cerevisiae, are already exploited for this reason as food additives. They may additionally contain, however, a wide range of substances not found in present day food and some may be undesirable either because they are directly harmful to the consumer or because they are in some way offensive. Organisms known to be safe are much more likely to be considered as potential sources of food than previously-untested micro-organisms because of the possible presence of toxic substances. This is particularly the case in the developed world where emphasis on the safety of new ingredients is pronounced and where the cost of establishing the safety of novel 
organisms may be large. Many 'normal' foods are harmful in some circumstances but are nevertheless regarded as acceptable; however, this does not eliminate the need for extensive testing of new microbial foods.

A number of organisms may be viewed as acceptable on the grounds that they have already been widely used or are known to be safe. A list of such organisms would contain the yeasts Saccharomyces cerevisiae and Candida utilis and a number of fungi including the common mushroom, Agaricus bisporus, and other macrofungi, together with a strain of Fusarium whose safety has been established in recent years by extensive toxicological tests. Among bacteria the methanol-utilizing organism which gives the product Pruteen (ICI Ltd) has been demonstrated to be safe for animal feeding and there is some presumption of safety associated with the lactic acid bacteria which have been widely used to manufacture pickled products (Vaughn, 1982) and produce acidified foods derived from milk (Davis, 1973; Lawrence \& Thomas, 1979). There is little experience of the value of algae, which are often unpleasant in flavour, but Spirulina has been eaten by Africans living on the shores of Lake Chad and by Aztec Indians in Mexico for many years (Anon., 1979).

The number of organisms likely to be used for human food is thus limited. If individual components such as proteins, carbohydrates or fats were extracted from the cells it may be possible to extend the range of organisms used as food ingredients; the production of these fractions achieves a degree of purification and separation from potentially-harmful material.

Microbes to be cultured for food require nutrients. If microbial biomass is to be a significant item in commerce and nutrition, then the quantities of nutrients required will also be significant and this raises questions about resource utilization. The principles governing the quantities of $\mathrm{C}$ source utilized and the yield of microbial biomass are well known. Growth of micro-organisms will be carried out in aerobic circumstances (because this gives more efficient use of $\mathrm{C}$ nutrient than anaerobic growth) and the yield of micro-organisms will be about half that of the $C$ compound provided, if this is carbohydrate. Greater yields are obtained when highly-reduced compounds serve as the nutrient, because oxygen is subsequently incorporated into the molecule. For example, the incorporation of $\mathrm{O}_{2}$ into the alkane molecule when it is used as the $\mathrm{C}$ source for microbial growth leads to an increase in molecular weight by a factor of approximately 2. As a result, the amount of microbial biomass obtained from alkanes is of the same order as the weight of alkanes consumed (Levi et al. I 979).

The bulk of the nutrients supplied for microbial growth will inevitably be derived from plants. Because utilizable carbohydrate in plant material is only a fraction of the total mass, and because the conversion into microbial mass is relatively inefficient, it is clearly more effective to utilize carbohydrate crops directly as food for man. Nevertheless, the efficiency of conversion is greater than that occurring when plant material is used for animal production. The conversion of plants into microbes followed by feeding the microbial biomass to animals is even less efficient than the direct utilization of plants by animals. 
The situation is somewhat different with regard to the use of algae because the energy of sunlight is utilized to convert carbon dioxide to carbohydrate. The question-mark over algal utilization relates much more to the magnitude of the resources necessary to ensure that adequate quantities of light and $\mathrm{CO}_{2}$ can be utilized to produce biomass on the large scale.

The production of micro-organisms is not likely to be a reasonable objective for bulk food production in conditions of extreme scarcity, for then the direct consumption of a crop would be more effective. These considerations do not apply in the special situation when the aim is to produce protein, when carbohydrate is supplied as an energy and $C$ source and inorganic nitrogen is present to allow protein synthesis. Such production of single cell protein (SCP) for use as human and animal feed has important possibilities for overcoming protein shortages.

Because the general principles of microbial cultivation on the large scale are well established, no technical difficulty is envisaged in producing SCP. An organism which is able to grow rapidly and with a high yield relative to the substrate supplied is preferred and it should ideally be readily separated from the growth medium at the end of the process. Additionally, the need for further processing should be minimal. These requirements are met by strains of the species listed previously as acceptable. The nutrient medium must contain a suitable source of biochemical energy together with the other nutrients required by the organism; these include the $\mathrm{O}_{2}$ necessary for aerobic respiration. Considerable efforts are made to optimize the production of microbial cells and efficiency of biomass formation is commonly assessed in terms of the consumption of carbohydrate and $\mathrm{O}_{2}$, for these components of the growth medium are the most costly.

It is because of the need to obtain a high conversion efficiency that continuous fermentation systems are preferred to batch ones in major industrial plants manufacturing SCP. In continuous production the conditions may be standardized in a way which is impossible in a batch process, where the environment inevitably changes with time as end-products of metabolism accumulate. Even in continuous systems, operation on the large scale produces the possibility that in parts of the very large vessels used the conditions may not be optimal. If $\mathrm{C}$ nutrient is added to a large vessel at only one point, for example, locally-high concentrations may reduce the efficiency of $\mathrm{O}_{2}$ consumption, and low concentrations elsewhere may lead to a temporary cessation of growth. Therefore, in the large plant used by ICI to produce Pruteen from methanol, substrate is added at several thousand points.

Turning to the nature of the substrates used, economics and the need for large inputs to produce large quantities of biomass restrict the range of materials which are suitable as $\mathrm{C}$ sources. In recent years very large plants have been designed to grow yeast (Candida spp.) using alkanes from oil as the $C$ source. The escalation of oil prices and political problems have led to the abandonment of such schemes in Western countries. In Russia, however, much biomass is produced using alkanes. The use of a substrate insoluble in water led to problems of contact with micro-organisms existing in the aqueous phase.

Recently, ICI have constructed a sophisticated plant using methanol as the C 
source for a bacterium, Methylophylus methylotrophus. Methanol is produced catalytically from methane to provide a convenient and inexpensive $\mathrm{C}$ source. The plant is able to produce approximately 70000 tonnes per annum of a protein-rich product suitable for use as feed for livestock. It is also noteworthy that the application of genetic engineering techniques has improved the efficiency of conversion of methanol to bacterial biomass (Windlass et al. 1980).

Molasses, a relatively-inexpensive nutrient, is also used commercially to grow yeast as SCP and it is, of course, the usual substrate for the production of bakers' yeast (Burrows, 1979). It is used world-wide to the extent of two million tonnes per year.

In addition to these major substrates, many other materials have been suggested for the production of SCP. Quite commonly these have been residues or wastes from other processes; as indeed is molasses. Perhaps the most abundant waste awaiting exploitation is the whey obtained in cheese manufacture (Meyrath \& Bayer, 1979). However, most wastes are available only in relatively-small quantities by comparison with alkanes or methanol. Examples of their use include the Symba process (Jarl, I 969), developed in Sweden for the utilization of starchy waste to produce biomass containing two yeasts, Candida utilis and Saccharomycopsis (Endomycopsis) fibuligera. Confectionery wastes have also been used to produce Candida utilis biomass. The primary objective in almost all these cases has been to reduce the organic matter present in the waste and so ease the problems of its disposal, rather than to grow and market the biomass. However, the income derived from biomass is welcome. Waste utilization processes, if they are to produce human food, will necessarily incur substantial costs in sterilizing the waste to eliminate potential pathogens; these costs may be prohibitive if the waste is relatively dilute. Furthermore, the uncertain composition of most waste streams, particularly with regard to harmful chemical contaminants, seems likely to restrict them to a minor role in the production of SCP.

Reference was made above to the harmful components which may be present in potentially-useful microbial biomass. In the case of yeast biomass, the major problem is the high content of nucleic acids, especially RNA, present in the cell. For human consumption the nucleic acid content has to be reduced substantially in order to prevent the formation of uric acid and the development of gout and of kidney stones: humans lack the urease $(E C$ 3.5.1.5) necessary to metabolize uric acid produced by the breakdown of nucleic acids. Processes have been developed for reducing the levels of RNA in yeast but the need to apply these leads to additional costs.

The costs of producing SCP are relatively high and protein from microbial sources is rarely competitive with vegetable protein produced, for example, from soya bean. When the scale is large and the technology of high standard, the costs may be broadly comparable if the value of soya-bean protein is towards the upper end of its cyclical pattern. Nevertheless, it is important to recognize that the future use of microbial protein as a major component of human food will require that (a) the cost of vegetable protein rises markedly, or (b) the demand for protein 
increases so that microbial protein is positively required to meet world needs, or (c) microbial protein can be shown to possess properties that merit a premium price. In this connection it will be the functional properties of protein in food that add value rather than the role of protein as an $\mathrm{N}$ source. To the extent that microbial protein can be shown to substitute for high value materials (e.g. egg albumen), substantial quantities can be used at an economic price. At present much study of the potential value of microbial proteins, and especially that of Saccharomyces and Candida for human consumption, is underway. Nevertheless, microbial SCP is unlikely to find a major role as a human food for some time until the economics become more acceptable.

\section{REFERENCES}

Anon. (1979). In Microbial Processes; Promising Technologies for Developing Countries, p. $3^{8}$. Washington, DC: National Academy of Sciences.

Burrows, S. (1979). In Economic Microbiology, vol. 4, pp. 32-64 [A. H. Rose, editor]. London: Academic Press.

Davis, J. G. (1973). In Lactic Acid Bacteria in Beverages and Food, pp. 245-263 [J. G. Carr, C. V. Cutting and G. C. Whiting, editors]. London: Academic Press.

Hayes, W. A. \& Wright, S. H. (1979). In Economic Microbiology, vol. 4, pp. 142-176 [A. H. Rose, editor]. London: Academic Press.

Jarl, K. (1969). Food Technology 23, 1009-1012.

Laskin, A. I. \& Lechevalier, H. (1973). Handbook of Microbiology, vol. 2. Cleveland: Chemical Rubber Company Press.

Lawrence, R. C. \& Thomas, T. D. (1979). Microbial Technology: Current State, Future Prospects, pp. 187-219. Cambridge: Cambridge University Press.

Levi, J. D., Shennan, J. L. \& Ebbon, G. P. (1979). In Economic Biology, vol. 4, pp. 362-419 [A. H. Rose, editor]. London: Academic Press.

Meyrath, J. \& Bayer, K. (I979). In Economic Microbiology, vol. 4, pp. 208-269 [A. H. Rose, editor]. London: Academic Press.

Rose, A. H. (editor) (1979). In Economic Microbiology, vol. 4, pp. 1-29. London: Academic Press.

Vaughn, R. H. (1982). In Prescott E Dunn's Industrial Microbiology, pp. 185-236 [G. Reed, editor]. Westport: AVI.

Windlass, J. D., Warsey, M. J., Pioli, E. M., Pioli, D., Barth, P. T., Atherton, K. T., Dart, E. C., Byrom, D., Powell, K. \& Senior, P. J. (1980). Nature, 287, 396-401. 